\title{
Method validation for fatigue testing in kingpins
}

\author{
Jonas Trento Buzzatti ${ }^{1}$ \\ Daniel Antonio Kapper Fabricio ${ }^{2}$ \\ Guilherme Vieira Braga Lemos ${ }^{1}$ \\ Hilton Rutsatz ${ }^{1}$ \\ Guilherme Kieckow ${ }^{1}$ \\ Fabiano Mattei $^{1}$ \\ Etiene Benini Mendes ${ }^{1}$
}

\begin{abstract}
Fatigue testing in kingpins consists in applying cyclic forces to simulate the mechanical loads experienced by this automotive component in practice. In this context, Laboratório de Metalurgia Física (LAMEF) has a quality system implemented as suggested by ISO/IEC 17025 standard, and for the test to be under the management structure, the method must be validated. Method validation is a documented evidence that represents the standardization and indicates its suitability for a certain purpose. Therefore, this work presents the method validation for fatigue tests in kingpins. Thus, selectivity, linearity, sensitivity, range, precision, accuracy, stability and robustness were used as validation criteria. The interpretation of each criterion showed a suitable performance and guaranteed the method validation according the methodology proposed.
\end{abstract}

Keywords: Method validation; Metrology; Fatigue testing; Kingpin.

\section{Introduction}

Product certification has been used to the Market and is an essential requirement of consumers aiming at quality and cost. Besides, certification is an instrument for industrial development and consumer protection, being recognized by society to raise or ensure the quality level of products, services, and companies.

On February, 2008, the National Institute of Metrology, Standardization and Industrial Quality (INMETRO) Ordinance No. 70/2008 was formalized, establishing compulsory certification for kingpins, used on the vehicles carrying dangerous goods and cargoes, and must be carried out by a Product Certification Body (OCP), duly accredited by INMETRO. In this context, an OCP does not necessarily have to perform all the stages of certification and may hire accredited bodies to perform specific functions. In Brazil, LAMEF is accredited to INMETRO, according to the NBR ISO/IEC 17025 [1], to perform fatigue tests in kingpins. This mechanical test is based on NBR NM-ISO 8716 [2] and consists in the application of cyclic forces that simulate the loads experienced by the kingpin.

To verify if the quality system is properly implemented, the method is required to be validated. Method validation is a documented proof that represents standardization. Also, validation should demonstrate that the method is suitable for its purpose. The main acceptance criteria often considered in a method validation are selectivity, linearity, sensitivity, range of work, precision, accuracy, stability, and robustness [3]. Therefore, Figure 1 shows the flowchart for a typical method validation (in the analytical cases).

Several approaches may be used to validate test methods. Roiffé et al. [4] analysed repeatability, intermediate accuracy, matrix interference, limit of quantification, linearity, carryover and robustness to validate new analytical method for the analysis of catecholamines and its biotransformation products.

Yanamoto et al. [5] evaluated selectivity, linearity, accuracy, precision, and sensitivity of flow cytometry-based analysis for human $\mathrm{T}$ cells in immunodeficient mouse blood. Still, Khamis et al. [6] assessed linearity, precision, accuracy, dilution integrity, selectivity, carryover, and stability to validate a method for the absolute quantification of amino/ phonel metabolites. Therefore, many works are related to the biological, pharmaceutical and chemical areas [4-5,7-12]. However, we have not found a method validation for fatigue tests in kingpins, as proposed in the current study.

The International Council for Harmonization (ICH) of technical requirements for pharmaceutical products of human use [13] discussed the validation of analytical procedures

\footnotetext{
${ }^{1}$ Laboratório de Metalurgia Física - LAMEF, Programa de Pós-graduação em Engenharia de Minas, Metalúrgica e de Materiais, PPGE3M, Universidade Federal do Rio Grande do Sul-UFRGS, Porto Alegre, RS, Brasil.

${ }^{2}$ Instituto Federal de Educação, Ciência e Tecnologia de Santa Catarina-IFSC, Chapecó, SC, Brasil.

*Corresponding author: jtbuzzatti@hotmail.com
}

2176-1523 (C) 2021. Buzzatti et al. Published by ABM. This is an Open Access article distributed under the terms of the Creative Commons Attribution License, which permits unrestricted use, distribution, and reproduction in any medium, provided the original work is properly cited. 
such as identification, impurities and quantitative tests of the active fraction in samples of medicaments or related components.

The guide to validation and analytical quality control [14], developed by Brazilian government agencies, divides physical-chemical tests into distinct groups and categories and indicates minimum parameters that should be assessed. In the analytical methods [15], some parameters may no longer be evaluated. It was also indicated that the method can be considered validated, even if some parameters do not fit the limits established, but they are well known and adequate to the objectives to be accomplished.

Methods validation is adaptable for numerous samplings and analysis. However, the validation criteria for mechanical tests are not usually reported. Therefore, the present work shows the method validation for fatigue tests in kingpins. Statistical tools were applied, adapted to the data acquisition of forces for fatigue testing. Thus, similarly to $[3,13,15-18]$, the criteria used were: selectivity, linearity, precision, accuracy, stability, and robustness and all the forces were acquired in laboratory tests.

\section{Materials and methods}

\subsection{Equipment}

The analysed results were obtained in kingpin fatigue tests done at LAMEF. The tests were performed on a bench test ( $250 \mathrm{kN}$ capacity (Figure 2 ). The horizontal forces aimed to simulate the loads experienced by the kingpins.

The force values were acquired through a force transducer (load cell), which was duly calibrated. A controller

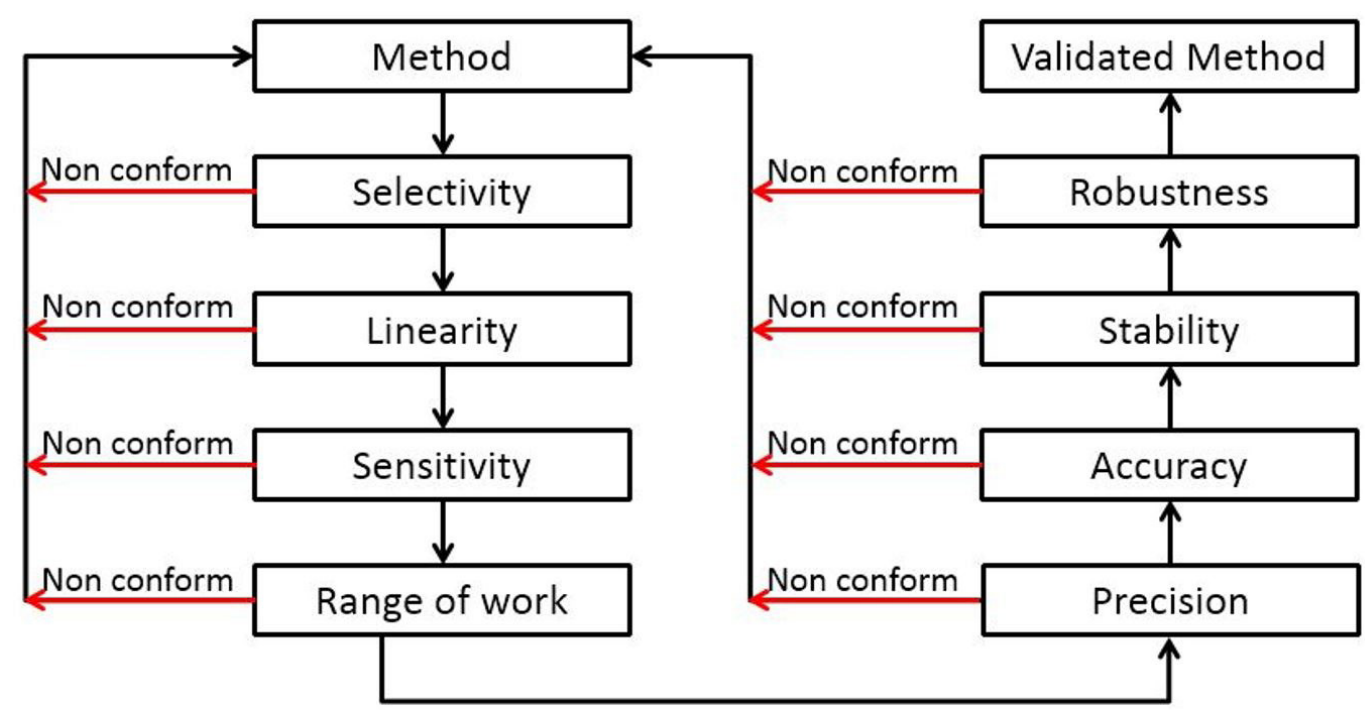

Figure 1. Flowchart for a method validation [Adapted from [2]].
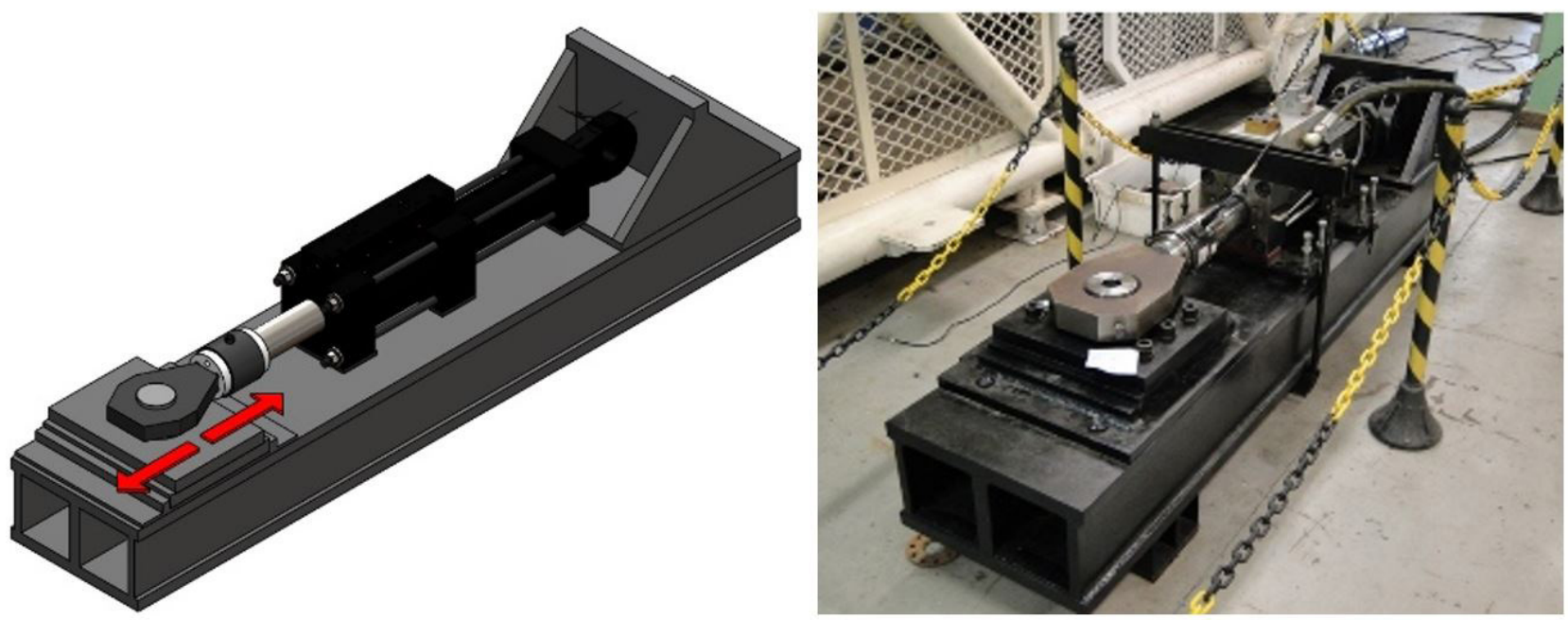

Figure 2. Bench test on kingpin. 
of the MTS brand FlexText (16 bits) performed the reading of force values by the load cell, equipped with the Station Manager 5.1C software. Thus, Figure 3 shows examples of the force transducers.

\subsection{Tested kingpin}

Kingpin is an automotive component that, along with the fifth wheel, links the horse to the semi-trailer in automotive wagons. There are several kingpin models (two shown in Figure 4) that can be exemplified as: 2 and 8-inch kingpin with 8 and 12 holes and 3.5-inch kingpin with 8 and 12 holes.

\subsection{Mechanical testing}

The kingpin fatigue test consists in applying horizontal forces perpendicularly to the pin axis, with a frequency of less than $30 \mathrm{~Hz}$, during 2,000,000 cycles. In the test, the values of maximum and minimum force are acquired and stored in every 100 cycles for further data analysis.

\subsection{Evaluated criteria}

In this work, the criteria (Figure 1) were selected for the method validation. Therefore, criteria are briefly described below.
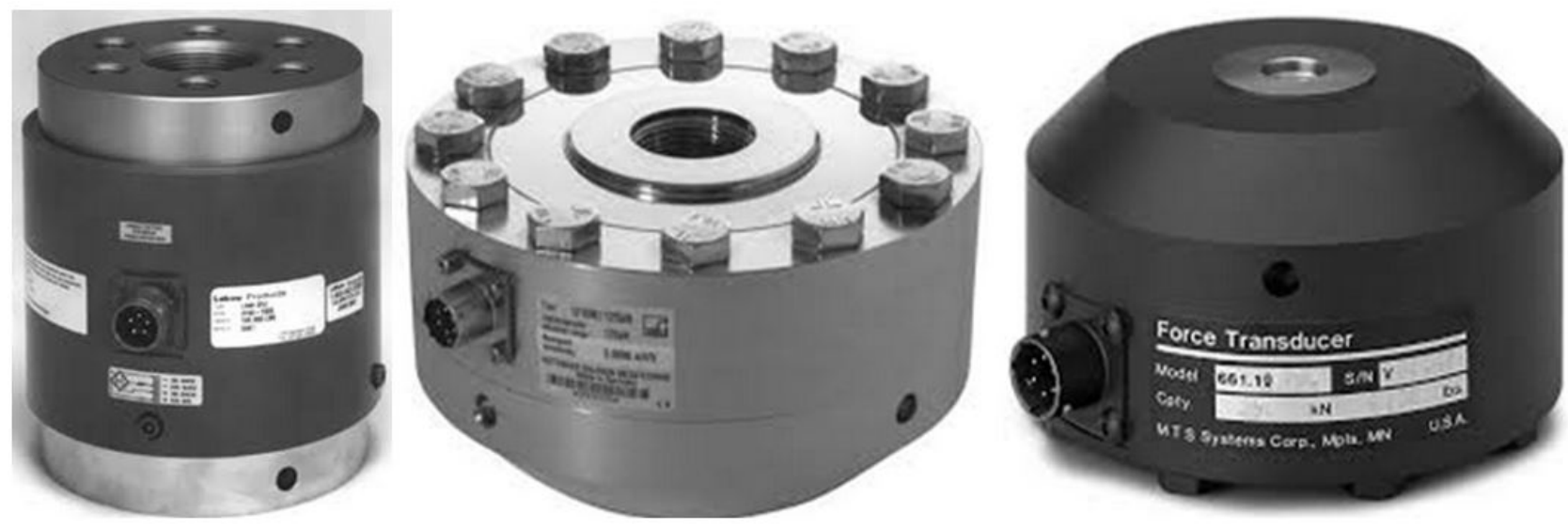

Figure 3. Some power transducer models available on the Market.
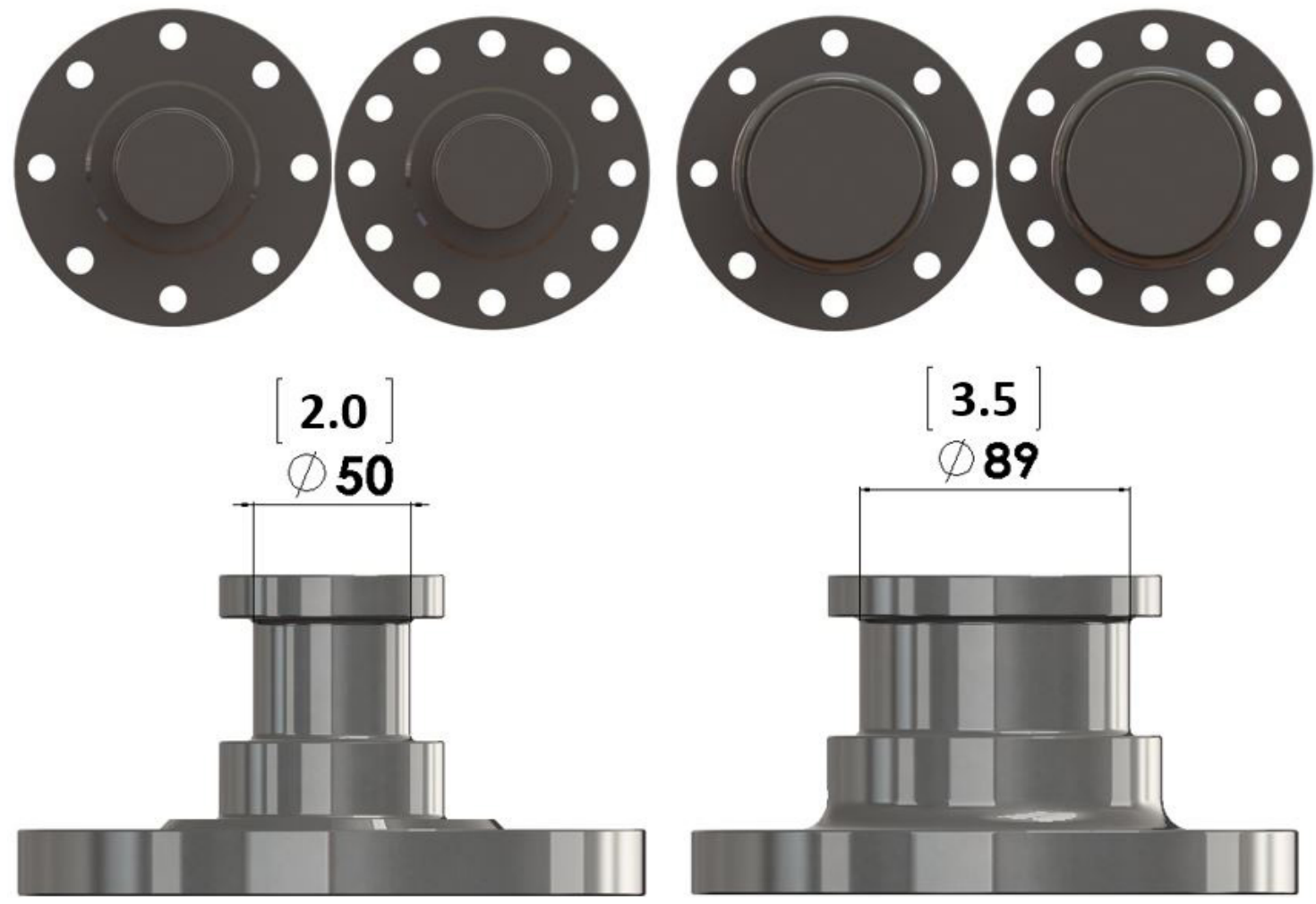

Figure 4. Kingpins: 2-inch with 8 and 12 holes (left) and 3.5-inch with 8 and 12 holes (right). 
When a sizing device can furnish values for one or higher measurands and these values are independent of each other, it can be understood as selectivity [14]. In analytical tests, it is considered as the capacity to unequivocally consider the analyte in the presence of components, as in International Conference on Harmonisation of Technical Requirements for Registration of Pharmaceuticals for Human Use [13].

Linearity is considered to produces outcomes immediately proportional to a reference value, inside a specified range [3]. The ICH Topic Q2 (R1) guideline [13] and the instruction on validation of analytical strategies of INMETRO [18] agree that linearity, in analytical methods, it is the capacity to produce consequences that are relative to the analyte in a given range.

Sensitivity establishes the variation of a response as a characteristic of analyte concentration in analytical tests [18]. In this sense, in Brito et al. [15], it was used to define that a small distinction in analyte concentration motives a significant variation in the value of the measured analytic signal in touchy methods.

Working range is the value for the method application. At its decrease limit, the elements are the limits of detection and quantification. At its upper limit, the limits depend on the response of the measuring tools [3]. Once the system has tested its accuracy, precision and linearity, the interval between the lowest and the best analyte awareness is viewed as an excellent working range [13]. Also, in Brito et al. [15], it was mentioned that the first assignment must be to pick the working to vary and determine whether the signal-toconcentration ratio is linear.

Precision is the estimation of consequences dispersion between repeated independent tests, samples or similar patterns underneath defined prerequisites and can be further described through reproducibility and repeatability $[13,18]$. According to Zoonen et al. [12], both usually depend on the analyte concentration.

Accuracy is the degree of agreement related to the result of size and the reference value (accepted as valid) [19]. In this context, the accuracy of an analytical test indicates levels of agreement between the measured cost and what is conventional as an actual conventional value [13].

Stability is the capability of the approach not to demonstrate developments that slash its degree of self-belief over the time [19]. It must be verified by way of simulating the stipulations under which the laboratory submits the samples and standards [8].

Evaluating the robustness should examine the ability to remain unchanged given small but controlled variations surrounding it $[10,14,18]$. Some authors mentioned that the robustness can be beneficial during the development phase [13], that is, in the process of previewing the method $[10,15]$. In a validation process, the robustness makes available the dimension of the problems that can occur when the method is repeated in different conditions [15].

\section{Results and discussion}

\subsection{Selectivity}

Unlike the analytical cases, in the kingpin fatigue test, there is no simultaneous presence of more than one measurand since the equipment is designed to apply the load on the kingpin at a time. However, it was observed whether the methodology is indifferent to its application in samples of distinct species (different kingpin models). Thus, ten cycles of four loads were analysed in varied kingpins (2.0 and 3.5 inches in diameter).

The $\mathrm{F}$ test was applied to verify sample variances that could be considered equal. At first, the value of $F_{\text {calculated }}$ was obtained according to Equation 1.

Then, this value was compared with $F_{\text {tabulated }}$, achieved in the $F$ distribution at a significance of $\alpha=0.05$ [20] for four measurements with $n-1$ repetitions (where $n$ is the sample size).

$$
F_{\text {calculated }}=\frac{S_{1}^{2}}{S_{2}^{2}}
$$

where $\mathrm{S}_{1}{ }^{2}$ and $\mathrm{S}_{2}{ }^{2}$ are the variances of each sample, with the greatest variance in the numerator. The criteria for interpreting the results are the following [3]:

- If $F_{\text {calculated }}<F_{\text {tabulated: }}$ the variances can be considered equal, the variety of different specimens of samples has no significant effect on the precision of the method.

- $\mathrm{f} F_{\text {calculated }}>F_{\text {tabulated }}:$ the variances are not equal and the variety of different specimens has an essential effect on the accuracy.

Appendix 1 shows the nominal values of forces for each model and the values measured in ten repetitions. Appendix 2 shows the calculated values of the mean, standard deviation, and variances. When $F_{\text {calculated }}<F_{\text {tabulated }}$, the variances can be considered equal, and it is interpreted that the variety of different specimens has no significant effect on the accuracy of the method, as noted here in Equation 4.

F test:

$$
\begin{aligned}
& \boldsymbol{F}_{\text {calculated }}=\frac{0.003435}{0.001826}=1.887 \\
& \boldsymbol{F}_{\text {tabulated }}=F(\alpha ; v 1 ; v 2)=F(0.05 ; 9 ; 4)=5.999 \\
& \boldsymbol{F}_{\text {calculated }}<\boldsymbol{F}_{\text {tabulated }}
\end{aligned}
$$

\subsection{Linearity}

The linearity was evaluated by the range of the applied loads. Thus, three cycles of six different forces were analysed. The linearity of the nominal force vs applied force curve 
was assessed, besides the randomness of the residual profile (Figure 5b). The Equation 5 relates the variables as follows:

$$
y=a x+b
$$

Where $y$ represents the measured response (applied force), $x$ is the nominal force; $a$ is the sensitivity and $b$ the intersection with the $y$-axis (when $x=0$ ). For acceptance, the criterion [3] used was:

- $\quad$ Ideal when $r>0.9$ and $R^{2}>0.99$

- Waste profile should indicate no trends.

Appendix 3 shows the nominal forces and three repetitions for each value, the mean of these repetitions and the calculated value of the residuals. In Figure 5a), nominal force vs average of applied forces can be observed, where the $\mathrm{R}^{2}$ value is greater than 0.99 , which is considered ideal. In Figure 5b), the residuals had a relatively homogeneous dispersion. Finally, the linearity has been proven through the ability to produce results directly to a reference value.

\subsection{Sensitivity}

The sensitivity was based on the equipment resolution during the loads. To that, the technical manuals of the transducer and the controller were consulted.

This resolution is subject to the arrangement between its capacity and the system adopted to read the acquired data (ABNT NBR ISO 376 [19]).

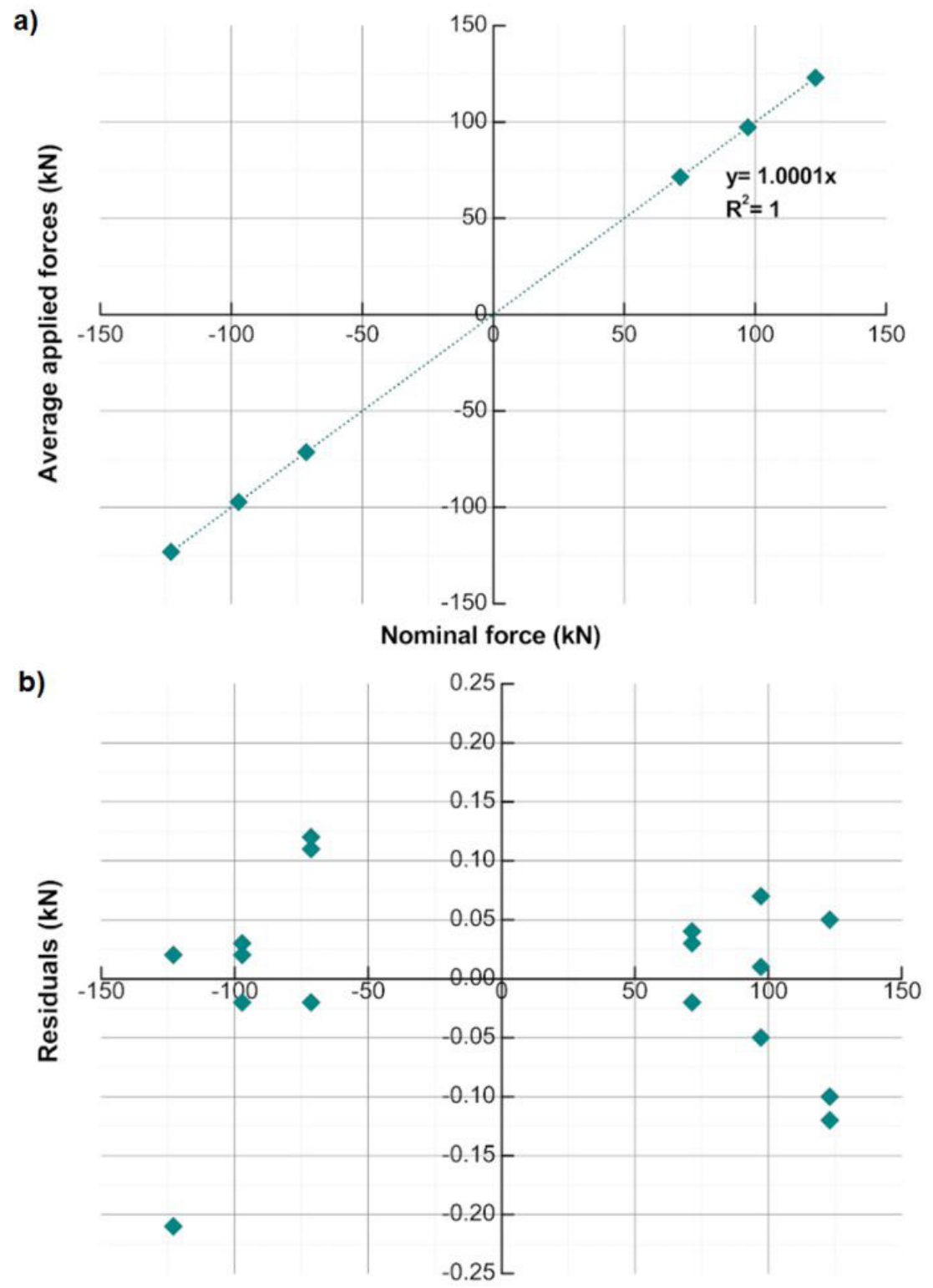

Nominal force $(k N)$

Figure 5. Linearity: (a) Average of applied forces vs nominal forces; (b) Dispersion of residuals. 
According to the technical manual [21], the equipment resolution is finite. The resolution is considered as the transducer range $(250 \mathrm{kN})$ divided by the lowest reading number $(216$ bits). The standard for calibration of the force transducer determines that the resolution for digital readers must be an increment of the last active digit of the numerical indicator. In the present study, the maximum resolution was $0.004 \mathrm{kN}$.

\subsection{Working range}

For the working range, the lower limit of the force transducer according to ABNT NBR ISO 376:2012 [19] (Equation 6) and the maximum load capacity supported by the transducer were taken into account.

$$
F_{\text {min }}=0.02 \times F_{f}
$$

Where $F_{f}$ is the maximum capacity of the force transducer, in Newton.

The technical specification of the Honeywell force transducer $(3156-50 \mathrm{~K}$ model) is $200 \mathrm{kN}$ for fatigue tests [21]. Thus, the lower limit of work was (Equation 7):

$$
F_{\text {min }}=0.02 \times 200000=4000 \mathrm{~N}=4 \mathrm{kN}
$$

All the forces applied were kept within the stipulated limits; therefore, the method maintained an adequate working range.

\subsection{Precision}

The performance of two analysts was used to evaluate the accuracy. Therefore, ten cycles of force applications were studied by two different analysts. Repeatability and reproducibility were observed, and the T-test was also applied. The values of the ten replications performed for each analyst, as well as the amplitude between these values, are presented in Appendix 4.

For repeatability and reproducibility $(\mathrm{R} \& \mathrm{R} \%)$, the Equation 8 was used:

$$
\sigma_{m}=\frac{R_{(\text {average })}}{d_{2}}=\frac{0.024}{1.16}=0.021
$$

Where R (average) is the mean of the amplitude and $\mathrm{d} 2$ is a parameter taken from Brasil [14], considering ten samples and two analysts.

The value of $\sigma_{m}$ was multiplied by the constant 5.15 [3], as shown in Equation 9.

$$
R \& R=5.15 \times \sigma_{m}=5.15 * 0.021=0.11
$$

After calculating the variation due to $R \& R$, this (R\&R) was verified by dividing its value by the total variability (VT) (Equation 10).

According to the NBR NM-ISO 8716 standard [2], the tolerance for the force is $+/-0.6$, so that $\mathrm{VT}$ is equal to 1.2 (Equation 10).

$$
R \& R \%=100 \times \frac{R \& R}{V T}=100 \times \frac{0.11}{1.2}=9.17 \%
$$

In order to evaluate the R\&R, what should be considered is Associação Brasileira de Normas Técnicas [1]:

- If $R \& R \%<10 \%$ : the method would be considered acceptable;

- If $10 \%<R \& R \%<30 \%$ : it would be considered acceptable but needs improvements;

- If $R \& R \%>30 \%$ : it would be considered unacceptable.

Since the $R \& R \%$ was less than $10 \%$, the method is acceptable. In addition to the repeatability and reproducibility, the T-test compared the performance of the two analysts. The test was executed using Excel and considered $\alpha=0.05$. The interpretation was done considering the following [15]:

- Stat $t<t_{\text {critical }}$ : analysts do not have significant differences in their results.

- Stat $>t_{\text {critical }}$ : evidences that analysts have significant changes in their results.

Table 1 presents the T-test result. The dispersion between analysts characterised the method as being accurate, since $\mid$ Stat- $t \mid<t_{\text {critical }}$ showed that analysts do not have substantial differences between their results.

\subsection{Accuracy}

To accuracy, the performance of two analysts was compared to the standard analyst (indicated by the signatory of the laboratory). Ten cycles of forces performed by two analysts were compared to ten cycles of force done by the standard analyst. The evaluation considered the Z-Score test. The test was carried out for each analyst individually and also considered the general average of the two analysts. Therefore, the Equation 11 for the Z-Score test was:

$$
Z=\frac{\left(X_{\text {analyst }}-X_{\text {standard }}\right)}{S}
$$

Table 1. T-test

\begin{tabular}{lcc}
\hline & $\begin{array}{c}\text { Analyst } \\
(\mathbf{k N})\end{array}$ & $\begin{array}{c}\text { Analyst 2 } \\
(\mathbf{k N})\end{array}$ \\
\hline Mean $(\mathrm{kN})$ & 123.005 & 123.013 \\
Variance $\left(\mathrm{kN}^{2}\right)$ & 0.00324 & 0.00334 \\
Observations & 10 & 10 \\
Pearson correlation & 0.870 & \\
Hypothesis of the mean difference & 0 & \\
$\mathrm{gl}$ & 9 & \\
Stat- $\mathrm{t}$ & -0.922 & \\
$\mathrm{P}(\mathrm{T}<=\mathrm{t})$ one-tailed & 0.190 & \\
$\mathrm{t}$ critical one-tailed & 1.833 & \\
$\mathrm{P}(\mathrm{T}<=\mathrm{t})$ two-tailed & 0.380 & \\
$\mathrm{t}$ critical two-tailed & 2.262 & \\
\hline
\end{tabular}


Where $X_{\text {analyst }}$ is the average obtained by the analysts (or the general average of the two analysts), $X_{\text {standard }}$ is the average obtained by the standard analyst, and $\mathrm{S}$ is the deviation achieved by the standard analyst. This evaluation was done according to the criteria below (Equation 12, 13 and 14):

- $|Z|<2$ : Satisfactory result;

- $2<|Z|<3$ : Questionable result;

- $|Z|>3$ : Unsatisfactory result.

Ten measurements of the standard analysts and two analysts are shown in Appendix 5. Based on these values, the overall Z-score was calculated for each analyst. The $Z$-score values verified for the two analysts separately and simultaneously, showing agreement between the measured and standard values, confirming the accuracy of the method (Equation 15, 16 and 17).

Z-score:

$$
\begin{aligned}
& Z_{\text {general }}=\frac{97.14-97.22}{0.10}=-0.79 \\
& Z_{\text {analyst } 1}=\frac{97.16-97.22}{0.10}=-0.52 \\
& Z_{\text {analyst } 2}=\frac{97.11-97.22}{0.10}=-1.06
\end{aligned}
$$

$|-0.79|<|2|$ : satisfactory result

$|-0.52|<|2|$ : satisfactory result

$|-1.06|<|2|$ : satisfactory result

All Z-scores were lower than the acceptance limit $|Z|<2$. Thus, according to Z-score, this method is accurate.

\subsection{Stability}

Twenty tests were selected, where the nominal force was the same $(97.2 \mathrm{kN})$. From each test, three values of applied force were taken to calculate means and deviations. These values can be seen in Appendix 6. The evaluation was done by control charts for averages and deviations.

The criteria for evaluating the results were [20]:

i. A value above the upper limit indicates that the process is out of control;

ii. Seven consecutive values creating trend (above or below the centre line) indicate that the process is out of control.

Appendix 7 shows the calculated values of means and deviations. The constants for the boundary calculations are found in Montgomery and Runger [20]. The control charts (Figure 6 and Figure 7) did not show trends outside of their limits that diminish the degree of confidence, both in the study of means and deviations, thus proving the stability.

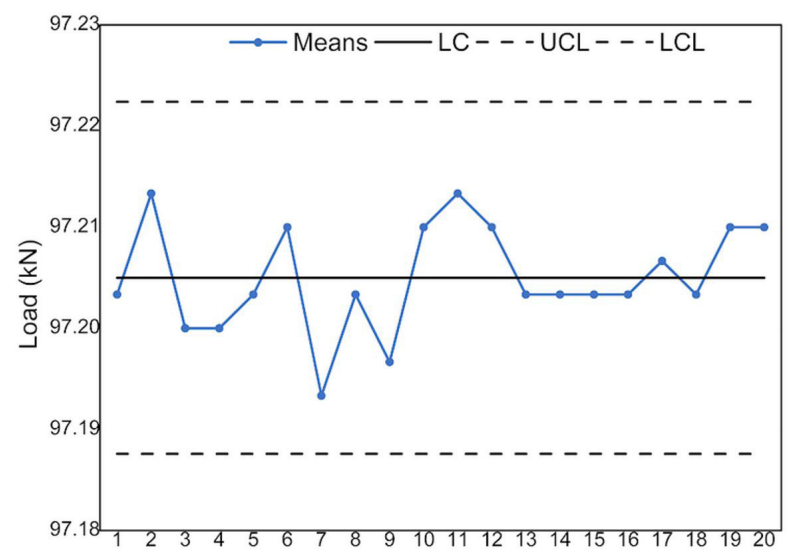

Figure 6. Control chart for means.

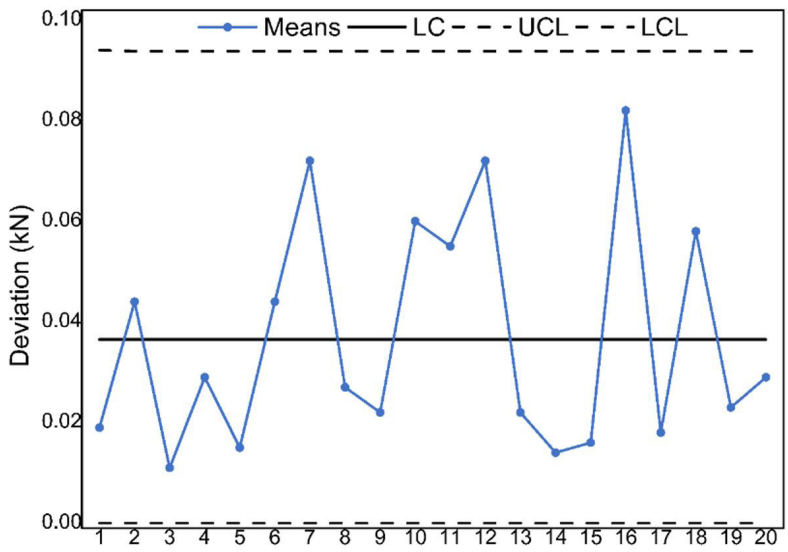

Figure 7. Control chart for deviations.

Control charts for means (Equation 18, 19 and 20):

$$
\begin{aligned}
& \boldsymbol{L C}=\text { average of means }=97.205 \\
& \boldsymbol{U C} \boldsymbol{L}=97.21+(3 \times 0.0058)=97.222 \\
& \boldsymbol{L C L}=97.21-(3 \times 0.0058)=97.188
\end{aligned}
$$

Control chart for deviations:

$\boldsymbol{L C}=$ mean of deviations $=0.037$

$\boldsymbol{U C} \boldsymbol{L}=0.037 \times B_{4}=0.037 * 2.57=0.094$

B4 taken from Montgomery and Runger [20].

$\boldsymbol{L C} \boldsymbol{L}=0.037 \times B_{3}=0.037^{*} 0.00=0.00$

B3 also taken from Mendes [7].

\subsection{Robustness}

The robustness was analysed by two factors: factor 1 - model of the item tested; factor 2 - analyst. Next, six 
replicates of forces applied by two analysts were selected in two kingpin models, with force applied as a response. The evaluation was done by comparing the robustness deviation with the variation due to R\&R. To calculate the robustness deviation, factors to be examined (e.g. factor $\mathrm{A}$ and factor B) and two quantitative levels for each factor (A1 and $\mathrm{A} 2$ or $\mathrm{B} 1$ and $\mathrm{B} 2$ ) were considered. After six replicates combining each factor (A1B1 and A1B2, A2B1 and A2B2) and calculating their means, the factor analysis was done by Equations 24 and 25 .

$$
\begin{aligned}
& D A=\frac{A_{1} B_{1}+A_{1} B_{2}}{2}-\frac{A_{2} B_{1}+A_{2} B_{2}}{2} \\
& D B=\frac{B_{1} A_{1}+B_{1} A_{2}}{2}-\frac{B_{2} A_{1}+B_{2} A_{2}}{2}
\end{aligned}
$$

Later, deviations were squared and summed to average, as shown in Equations 26 and 27.

$$
\begin{aligned}
& D^{2}=D A^{2}+D B^{2} \\
& M=\frac{D^{2}}{2}
\end{aligned}
$$

The robustness deviation is calculated by Equation 28 .

$$
S_{r}=\sqrt{2 \times M}
$$

The deviation of the reproducibility was calculated by Equation 5 for each factor.

i. Two analysts testing 2.0-inch model

ii. Two analysts testing 3.5-inch model

iii. Two models being tested by analyst $\mathrm{A}$

iv. Two models being tested by analyst B

The comparison of the robustness deviation with $R \& R$ variation was made as follows $[1,22,23]$ :

If $S_{r}<\sigma_{m}$, the method is considered robust.

Ten repetitions with two varied analysts applying the load on two different kingpin models, and their means are shown in Appendix 8. The amplitude measured for each analyst and model is presented in Appendix 9. Thus, the robustness deviation $\left(S_{r}\right)$ is lower than reproducibility deviation in the four cases, showing that the results are not sensitive to alterations of analysts and kingpin models, demonstrating satisfactory robustness of the method.

Analyses of effects (Equation 29, 30, 31 and 32):

$$
\begin{aligned}
& D_{\text {model }}=\frac{(97.1876+97.1948)}{2}-\frac{(97.1805+97.1886)}{2}=0.0067 \quad D_{\text {model }}^{2}=0.0067 \\
& D_{\text {analyst }}=\frac{(97.1876+97.1886)}{2}-\frac{(97.1805+97.1948)}{2}=0.0005 \quad D_{\text {analyst }}^{2}=0.0005 \\
& M=\frac{0.0067+0.0005}{2}=0.000024 \\
& S_{r}=\sqrt{2 \times 0.000024}=0.0067
\end{aligned}
$$

Deviation from reproducibility:

Model 2.0 tested by two analysts (A and B):

$\sigma_{m 2.0}=0.0384 / 1.1600=0.0331$

Model 3.5 tested by two analysts: $\sigma_{m 3.5}=0.0303 / 1.1600=0.0262$ Analyst " $\mathrm{A}$ " testing two models (2.0 and 3.5):

$\sigma_{m A}=0.0343 / 1.1600=0.0295$

Analyst "B" testing two models (2.0 and 3.5):

$\sigma_{m B}=0.0295 / 1.1600=0.0255$

$0.0067<0.0331$

$0.0067<0.0262$

$0.0067<0.0295$

$0.0067<0.0255$

The robustness deviation value $\left(S_{r}\right)$ was lower than all R\&R deviation (Equation 36, 37, 38 and 39). Therefore, the test method is robust.

\section{Conclusions}

This work presented the method validation for fatigue tests in kingpins. The findings can be summarised as follows:

- The validation criteria were applied in a method involving mechanical forces. The interpretation of each criterion showed excellent performance of the method and guaranteed its validation;

- In the selectivity evaluation, $F_{\text {calculated }}(1.887)<F_{\text {tabulated }}$ (5.999), which is satisfactory;

- Concerning linearity, $R^{2}$ was greater than 0.99 , which is suitable;

- In the accuracy evaluation, $R \& R \%$ value was $9.17 \%$ (below the $10 \%$ minimum). In addition, it can also be approved for accuracy because all Z-scores were less than 2;

- The control charts for means and variables showed that there were no out-of-control points, thus the test is stable;

- Since $S_{r}$ values were lower than $\sigma_{m}$, the method is robust;

- Sensitivity and range were not evaluated. Both criteria, which take into account the limit of detection of the equipment, can be based on the result of the force transducer;

- Considering all analysed criteria (selectivity, linearity, sensitivity, precision, accuracy, and others), the test method can be considered validated. 


\section{References}

1 Associação Brasileira de Normas Técnicas. NBR ISO/IEC 17025: 2017. Requisitos gerais para competência de laboratórios de ensaio e calibração. Rio de Janeiro: ABNT; 2017.

2 Associação Brasileira de Normas Técnicas. NBR NM-ISO 8716: 2001. Veículos rodoviários comerciais - Pino rei para quinta roda - Ensaio de resistência. Rio de Janeiro: ABNT; 2001.

3 Albano F, Raya-Rodriguez MT. Validação e garantia da qualidade de ensaios laboratoriais. Porto Alegre: Rede Metrológica RS; 2009.

4 Roiffé R, Ribeiro WD, Sardela VF, Cruz MNS, Souza KR, Pereira HMG, et al. Development of a sensitive and fast method for detection of catecholamines and metabolites by HRMS. Microchemical Journal. 2019;150:104173.

5 Yanamoto S, Matsumoto S, Shimizu H, Hirabayashi H. Quantitative application of flow cytometry for the analysis of circulating human T cells: a preclinical pharmacokinetic study. Drug Metabolism and Pharmacokinetics. 2020;35(2):207-213.

6 Khamis MM, Adamko DJ, El-Aneed A. Development of a validated LC- MS/MS method for the quantification of 19 endogenous asthma/COPD potential urinary biomarkers. Analytica Chimica Acta. 2017;989:45-58.

7 Mendes EB. Ensaios de avaliação da conformidade de produtos em visitas à certificação [dissertação]. Porto Alegre: Universidade Federal do Rio Grande do Sul; 2010.

8 Miller JN. Statistics and chemometrics for analytical chemistry. Londres: Pearson Education; 2010.

9 Oliveira CC, Granato D, Caruso MSF, Sakuma AM. Manual para elaboração de cartas de controle para monitoramento de processos de medição quantitativos em laboratórios de ensaios. São Paulo: Secretaria da Saúde; 2013.

10 Tiwari G, Tiwari R. Bioanalytical method validation: an updated review. Pharmaceutical Methods. 2010;1(1):25-38.

11 U.S. Department of Health and Human Services. Analytical procedures and methods validation for drugs and biologics-guidance for industry. Washington: U.S. Department of Health and Human Services; 2015.

12 Zoonen VP, Klooster VT, Hoogerbrugge R, Grot SM, Wiel HJV. Validation of analitycal methods and laboratory procedures for chemical measurements. Arhiv za higijenu rada i toksikologij. 1998;49(4):355-370.

13 International Conference on Harmonisation of Technical Requirements for Registration of Pharmaceuticals for Human Use. ICH Q2(R1) Validation of Analytical Procedures: Text and Methodology. Complementary Guideline of Methodology. USA: ICH; 1996.

14 Brasil. Ministério da Agricultura, Pecuária e Abastecimento. Guia de validação e controle de qualidade analítica. Brasília: Ministério da Agricultura, Pecuária e Abastecimento; 2011.

15 Brito NM, Amarante OP Jr, Polese L, Ribeiro ML. Validação de métodos analíticos: estratégia e discussão. Pesticidas: Revista de Ecotoxicologia e Meio Ambiente. 2003;13:129-146.

16 AOAC International. AOAC Official methods of analysis. Appendix D: guideline for collaborative study procedures to validate characteristics of a method of analysis. Rockville: AOAC International; 2002. p. 1-12.

17 Huber L. Validation and qualification in analytical laboratories. Boca Raton: CRC Press; 2007.

18 Instituto Nacional de Metrologia. Qualidade e tecnologia. Orientação sobre validação de métodos analíticos. Brasília: INMETRO; 2011.

19 Associação Brasileira de Normas Técnicas. ABNT NBR ISO 376: 2012. Metallic materials - Calibrations of forceproving instruments used for the verification of uniaxial testing machines. Rio de Janeiro: ABNT; 2012.

20 Montgomery DC, Runger GC. Estatística aplicada e probabilidade para engenheiros. 5. ed. Rio de Janeiro: LTC; 2012.

21 Honeiwell. Model 3156 canister load cell datasheet. Honeywell; 2008 [cited 2020 Nov 11]. Available at: https:/sensing. honeywell.com/honeywell-test-and-measurement-model-3156-canister-load-cell-product-sheet-008645-1-en.pdf

22 Instituto Nacional de Metrologia. Coordenação Geral de Credenciamento. Introdução à validação de método. Brasília: INMETRO; 2006 [cited 2020 Nov 11]. Available at: http://www.inmetro.gov.br/metcientifica/palestras/ renata\%20borges.pdf

23 Instituto Nacional de Metrologia, Qualidade e Tecnologia. Vocabulário Internacional de Metrologia. Conceitos fundamentais e gerais e termos associados. Brasília: INMETRO; 2011.

Received: 21 Aug. 2020

Accepted: 17 Dec. 2020 
Appendix 1. Nominal force values and kingpin models

\begin{tabular}{cccccccccccc}
\hline Model & $\begin{array}{c}\text { Nominal } \\
\text { Points }\end{array}$ & $\mathbf{1}(\mathbf{k N})$ & $\mathbf{2}(\mathbf{k N})$ & $\mathbf{3}(\mathbf{k N})$ & $\mathbf{4}(\mathbf{k N})$ & $\mathbf{5}(\mathbf{k N})$ & $\mathbf{6}(\mathbf{k N})$ & $\mathbf{7}(\mathbf{k N})$ & $\mathbf{8}(\mathbf{k N})$ & $\mathbf{9}(\mathbf{k N})$ & $\mathbf{1 0}(\mathbf{k N})$ \\
\hline $2.0 ”$ & 97.20 & 97.13 & 97.19 & 97.17 & 97.23 & 97.19 & 97.13 & 97.16 & 97.14 & 97.10 & 97.20 \\
& 71.40 & 71.43 & 71.44 & 71.38 & 71.39 & 71.43 & 71.41 & 71.44 & 71.38 & 71.39 & 71.41 \\
& -71.40 & -71.42 & -71.28 & -71.29 & -71.41 & -71.39 & -71.34 & -71.40 & -71.48 & -71.43 & -71.32 \\
& -97.20 & -97.19 & -97.14 & -97.14 & -97.17 & -97.14 & -97.15 & -97.17 & -97.22 & -97.13 & -97.14 \\
$3.5 ”$ & 123.00 & 123.05 & 122.90 & 122.88 & 123.07 & 123.03 & 122.96 & 123.00 & 123.01 & 122.95 & 122.94 \\
& 97.20 & 97.27 & 97.15 & 97.21 & 97.15 & 97.19 & 97.14 & 97.23 & 97.17 & 97.17 & 97.21 \\
& -97.20 & -97.18 & -97.22 & -97.17 & -97.23 & -97.23 & -97.15 & -97.20 & -97.16 & -97.17 & -97.22 \\
& -123.00 & -122.98 & -122.98 & -123.21 & -123.06 & -123.04 & -123.08 & -123.02 & -122.91 & -122.95 & -123.00 \\
\hline
\end{tabular}

Appendix 2. Calculation and mean of variances

\begin{tabular}{|c|c|c|c|c|}
\hline Model & $\begin{array}{c}\text { Nominal Points } \\
(\mathbf{k N})\end{array}$ & $\begin{array}{c}\text { Measurements Average } \\
(\mathrm{KN})\end{array}$ & $\begin{array}{c}\text { Standard Deviation } \\
(\mathbf{k N})\end{array}$ & $\begin{array}{c}\text { Variance } \\
\left(\mathrm{kN}^{2}\right)\end{array}$ \\
\hline \multirow[t]{5}{*}{$2.0 "$} & 97.20 & 97.16 & 0.038114 & 0.001453 \\
\hline & 71.40 & 71.41 & 0.024907 & 0.00062 \\
\hline & -71.40 & -71.38 & 0.066016 & 0.004358 \\
\hline & -97.20 & -97.13 & 0.029521 & 0.000871 \\
\hline & \multicolumn{4}{|c|}{ Mean of the variances $\left(\mathrm{kN}^{2}\right) 0.001826$} \\
\hline \multirow[t]{5}{*}{$3.5 "$} & 123.00 & 122.98 & 0.064612 & 0.004175 \\
\hline & 97.20 & 97.149 & 0.040524 & 0.001642 \\
\hline & -97.20 & -97.19 & 0.03147 & 0.00099 \\
\hline & -123.00 & -123.02 & 0.083502 & 0.006973 \\
\hline & \multicolumn{4}{|c|}{ Mean of the variances $\left(\mathrm{kN}^{2}\right) \mathbf{0 . 0 0 3 4 4 5}$} \\
\hline
\end{tabular}

Appendix 3. Values of the nominal forces, its three repetitions, calculated values of means and residuals

\begin{tabular}{|c|c|c|c|c|}
\hline Points & $\begin{array}{c}\text { Nominal Force } \\
(\mathrm{kN})\end{array}$ & $\begin{array}{c}\text { Applied Force } \\
(\mathrm{kN})\end{array}$ & $\begin{array}{c}\text { average applied forces } \\
(\mathrm{kN})\end{array}$ & $\begin{array}{c}\text { Residuals } \\
(\mathbf{k N})\end{array}$ \\
\hline 1 & 123.00 & 123.05 & 122.95 & 0.05 \\
\hline 2 & & 122.90 & & -0.10 \\
\hline 3 & & 122.88 & & -0.12 \\
\hline 4 & 97.20 & 97.27 & 97.21 & 0.07 \\
\hline 5 & & 97.15 & & -0.05 \\
\hline 6 & & 97.21 & & 0.01 \\
\hline 7 & 71.40 & 71.43 & 71.42 & 0.03 \\
\hline 8 & & 71.44 & & 0.04 \\
\hline 9 & & 71.38 & & -0.02 \\
\hline 10 & -71.40 & -71.42 & -71.33 & -0.02 \\
\hline 11 & & -71.28 & & 0.12 \\
\hline 12 & & -71.29 & & 0.11 \\
\hline 13 & -97.20 & -97.18 & -97.19 & 0.02 \\
\hline 14 & & -97.22 & & -0.02 \\
\hline 15 & & -97.17 & & 0.03 \\
\hline 16 & -123.00 & -122.98 & -123.06 & 0.02 \\
\hline 17 & & -122.98 & & 0.02 \\
\hline 18 & & -123.21 & & -0.21 \\
\hline
\end{tabular}


Appendix 4. Replication values of the two analysts and amplitude

\begin{tabular}{cccc}
\hline Cycles & Analyst 1 (kN) & Analyst 2 (kN) & Amplitude (kN) \\
\hline 1 & 123.026 & 123.051 & 0.025 \\
2 & 123.007 & 122.982 & 0.025 \\
3 & 123.018 & 122.988 & 0.030 \\
4 & 122.996 & 123.019 & 0.023 \\
5 & 122.871 & 122.896 & 0.025 \\
6 & 123.091 & 123.116 & 0.025 \\
7 & 123.035 & 123.039 & 0.004 \\
8 & 122.968 & 123.018 & 0.050 \\
9 & 123.032 & 123.022 & 0.010 \\
10 & 123.002 & 122.979 & 0.023 \\
& Average amplitude & & 0.024 \\
\hline
\end{tabular}

Appendix 5. Repetitions of the group coordinator as standard, of analyst 1 and analyst 2

\begin{tabular}{cccc}
\hline Sample & Standard $(\mathbf{k N})$ & Analyst 1 (kN) & Analyst 2 (kN) \\
\hline 1 & 97.40 & 97.13 & 97.12 \\
2 & 97.25 & 97.19 & 97.16 \\
3 & 97.32 & 97.17 & 97.06 \\
4 & 97.18 & 97.23 & 97.09 \\
5 & 97.18 & 97.19 & 97.10 \\
6 & 97.18 & 97.13 & 97.12 \\
7 & 97.21 & 97.16 & 97.09 \\
8 & 97.21 & 97.14 & 97.12 \\
9 & 97.22 & 97.10 & 97.13 \\
10 & 97.00 & 97.20 & 97.09 \\
Averages & 97.22 & 97.16 & 97.11 \\
Deviation & 0.10 & 0.04 & 0.03 \\
\hline
\end{tabular}

Appendix 6. Values of forces acquired during twenty different trials

\begin{tabular}{cccccccccc}
\hline $\mathbf{1}(\mathbf{k N})$ & $\mathbf{2}(\mathbf{k N})$ & $\mathbf{3}(\mathbf{k N})$ & $\mathbf{4}(\mathbf{k N})$ & $\mathbf{5}(\mathbf{k N})$ & $\mathbf{6}(\mathbf{k N})$ & $\mathbf{7}(\mathbf{k N})$ & $\mathbf{8}(\mathbf{k N})$ & $\mathbf{9}(\mathbf{k N})$ & $\mathbf{1 0}(\mathbf{k N})$ \\
\hline 97.18 & 97.26 & 97.21 & 97.22 & 97.20 & 97.16 & 97.18 & 97.18 & 97.17 & 97.21 \\
97.22 & 97.20 & 97.20 & 97.21 & 97.22 & 97.23 & 97.13 & 97.20 & 97.20 & 97.15 \\
97.21 & 97.18 & 97.19 & 97.17 & 97.19 & 97.24 & 97.27 & 97.23 & 97.22 & 97.27 \\
\hline $\mathbf{1 1}(\mathbf{k N})$ & $\mathbf{1 2}(\mathbf{k N})$ & $\mathbf{1 3}(\mathbf{k N})$ & $\mathbf{1 4}(\mathbf{k N})$ & $\mathbf{1 5}(\mathbf{k N})$ & $\mathbf{1 6}(\mathbf{k N})$ & $\mathbf{1 7}(\mathbf{k N})$ & $\mathbf{1 8}(\mathbf{k N})$ & $\mathbf{1 9}(\mathbf{k N})$ & $\mathbf{2 0}(\mathbf{k N})$ \\
\hline 97.28 & 97.13 & 97.19 & 97.19 & 97.20 & 97.12 & 97.23 & 97.14 & 97.19 & 97.24 \\
97.19 & 97.28 & 97.23 & 97.21 & 97.19 & 97.21 & 97.19 & 97.26 & 97.21 & 97.18 \\
97.17 & 97.22 & 97.19 & 97.21 & 97.22 & 97.28 & 97.20 & 97.21 & 97.23 & 97.21 \\
\hline
\end{tabular}

Appendix 7. Means and deviations acquired during twenty different trials

\begin{tabular}{lcccccccccc}
\hline & $\mathbf{1}$ & $\mathbf{2}$ & $\mathbf{3}$ & $\mathbf{4}$ & $\mathbf{5}$ & $\mathbf{6}$ & $\mathbf{7}$ & $\mathbf{8}$ & $\mathbf{9}$ & $\mathbf{1 0}$ \\
\hline Means & 97.20 & 97.21 & 97.20 & 97.20 & 97.20 & 97.21 & 97.19 & 97.20 & 97.20 & 97.21 \\
Deviations & 0.019 & 0.044 & 0.011 & 0.029 & 0.015 & 0.044 & 0.072 & 0.027 & 0.022 & 0.060 \\
& $\mathbf{1 1}$ & $\mathbf{1 2}$ & $\mathbf{1 3}$ & $\mathbf{1 4}$ & $\mathbf{1 5}$ & $\mathbf{1 6}$ & $\mathbf{1 7}$ & $\mathbf{1 8}$ & $\mathbf{1 9}$ & $\mathbf{2 0}$ \\
Means & 97.21 & 97.21 & 97.20 & 97.20 & 97.20 & 97.20 & 97.21 & 97.20 & 97.21 & 97.21 \\
Deviations & 0.055 & 0.072 & 0.022 & 0.014 & 0.016 & 0.082 & 0.018 & 0.058 & 0.023 & 0.029 \\
\hline
\end{tabular}


Appendix 8. Ten repetitions of loads applied by two different analysts in two distinct models of kingpins

\begin{tabular}{ccccc}
\hline Repetitions & $\mathbf{2 . 0}-$ analyst $\mathbf{A}(\mathbf{k N})$ & $\mathbf{3 . 5}-$ analyst B (kN) & $\mathbf{2 . 0}$ analyst B (kN) & $\mathbf{3 . 5}$ analyst A (kN) \\
\hline 1 & 97.1290 & 97.1485 & 97.1601 & 97.1744 \\
2 & 97.1857 & 97.2116 & 97.1447 & 97.1743 \\
3 & 97.1676 & 97.1470 & 97.1995 & 97.2107 \\
4 & 97.2256 & 97.1938 & 97.1982 & 97.2024 \\
5 & 97.2214 & 97.1856 & 97.2048 & 97.1863 \\
6 & 97.1925 & 97.1745 & 97.2301 & 97.1984 \\
7 & 97.2198 & 97.1935 & 97.1847 & 97.1427 \\
8 & 97.2137 & 97.1827 & 97.2214 & 97.1941 \\
9 & 97.1896 & 97.1410 & 97.1537 & 97.1994 \\
10 & 97.1316 & 97.2264 & 97.2513 & 97.2037 \\
Means & 97.1876 & 97.1805 & 97.1948 & 97.1886 \\
\hline
\end{tabular}

Appendix 9. Factor amplitudes compared separately

\begin{tabular}{ccccc}
\hline Repetitions & $\begin{array}{c}\text { Model 2.0/ } \\
\text { analyst A and B }\end{array}$ & $\begin{array}{c}\text { Model 3.5/ } \\
\text { analyst A and B }\end{array}$ & $\begin{array}{c}\text { Analyst A/ } \\
\text { model 2.0 and 3.5 }\end{array}$ & $\begin{array}{c}\text { Analyst B / } \\
\text { model 2.0 and 3.5 }\end{array}$ \\
\hline 1 & 0.0312 & 0.025969 & 0.045453 & 0.011672 \\
2 & 0.0410 & 0.037266 & 0.011383 & 0.066891 \\
3 & 0.0319 & 0.063726 & 0.043054 & 0.052578 \\
4 & 0.0274 & 0.008555 & 0.023218 & 0.004375 \\
5 & 0.0166 & 0.0007 & 0.0351 & 0.0192 \\
6 & 0.0376 & 0.0239 & 0.0059 & 0.0556 \\
7 & 0.0351 & 0.0508 & 0.0771 & 0.0088 \\
8 & 0.0077 & 0.0114 & 0.0196 & 0.0387 \\
9 & 0.0360 & 0.058375 & 0.009789 & 0.012625 \\
10 & 0.1197 & 0.02275 & 0.072086 & 0.024867 \\
Means & 0.0384 & 0.0303 & 0.0343 & 0.0295 \\
\hline
\end{tabular}

